International Journal of Linguistics, Literature and Translation (IJLLT)

ISSN: 2617-0299 (Online); ISSN: 2708-0099 (Print)

DOI: $10.32996 / \mathrm{jjllt}$

Journal Homepage: www.al-kindipublisher.com/index.php/ijllt

\title{
Teaching Interpreting: Tashkent State University of Uzbek Language and Literature Experience
}

Sayfullaev Anvar Islamovich

PhD, Senior Teacher of Tashkent State University of Uzbek Language and Literature, Uzbekistan

Corresponding Author: Sayfullaev Anvar Islamovich, E-mail: anvars-sayfullaev@mail.ru

\section{ARTICLE INFORMATION}

Received: November 05, 2020

Accepted: December 17, 2020

Volume: 3

Issue: 12

DOI: 10.32996/ijltt.2020.3.12.7

\section{KEYWORDS}

Interpretation, competence, professional competences, personal competences, start preinterpreting training, "Ping-Pong" activities

\section{ABSTRACT}

The purpose of this study is to suggest some effective ways of training interpreters and to share the experience of Tashkent state university of Uzbek Language and Literature named after Alisher Navoi with the same purpose of interpreter training. More specifically, it deals with theoretical views of different scholars about simultaneous interpreting to understand what actions the process of simultaneous interpreting involves and what skills a person is required to have in order to carry out this task. Training simultaneous interpreting is very complicated and complex task because it involves a great number of objectives to be realized. The concern of our investigation is the methods of teaching interpreting, the ways to make interpreter training i more effective and efficient. The reason why we undertook this research is that even though a lot have been done in this field of study by many scholars of the world, the problems specific to training interpreters in such language pair as Uzbek- English has still remained untouched. The article shares experiences of university staff about linguistic competency of interpreters, their aptitude to work in stressful settings, deep and well-structured background knowledge, ability to anticipate the words to be used in phrases, and their ability to apply various techniques that help them in interpreting task as their career. After the establishment of Tashkent state University of Uzbek Language and Literature named after Alisher Navai in 2016, professor Sh.S. Sirojiddinov, its rector, and specialists interpreters training took the course towards developing special programs targeting at holding the conference for training interpreters becoming qualified in translating from Uzbek into English and vice versa. The President of Uzbekistan Sh. Mirziyoyev considered this program as one of the priority tasks demanded for the administration and staff of university administrators and staff. The decision was motivated by the shortage of highly qualified interpreters who can interpret from Uzbek into English and from English into Uzbek during international conferences and forums.

\section{Introduction}

As it is widely known, with the evolution of international relations, there is an ever-growing need for professionals who can speak foreign languages and can mediate communication among people speaking different languages. Although some people believe that in the future the development of technology and artificial intelligence with special soft programs will reach such a level that there will be no need for human translators, scientists are convinced that even the most advanced translation programs such as Systran, PROMT and Personal Translator will need human-translators to edit their work. Moreover, the quality of machined oral translations leaves much to be desired.

So, for many years ahead, if not forever, human translation and interpreting will remain the best. This is the case each interpreter training course organizers must attempt to consider in order to develop programs and curricula fitting the needs of learners.

K C AL-KINDI CENTER

$\mathbf{R}$ D FOR RESEARCHA Your gateway to world-doss research
Published by Al-KindiCenter for Research and Development. Copyright (c) the author(s). This is an open access article under CC BY license (https://creativecommons.org/licenses/by/4.0/) 
In our university, we have been studying the experience of other universities in Uzbekistan and abroad and probing various related activities that would be the most appropriate for our students working with the language combination namely, Uzbek-English interpreting.

\section{Research Methods and Sources}

As Tashkent state university of Uzbek Language and Literature named after Alisher Navoi was established only a few years ago, training interpreters as one of the main objectives of the university was prioritized during the visit of the President Shavkat Mirziyoyev at the opening ceremony of the university. However before starting, the initial task of the team was to identify materials and methods of training

In order to start interpreters training, one should understand what knowledge, aptitudes, and skills people of this trade need to be qualified with. Therefore, we found it reasonable to start with analyzing what 'interpreting' means.

According to Weber (1984), "Interpretation is the oral transposition of an orally delivered message at a conference or a meeting from a source language into a target language, performed in the presence of the participants. This function can be performed simultaneously (at the same time as the speech is given) or consecutively (after the speaker has finished a part or the totality of the speech)" (Weber, p. 9, 1984).

In the same source he describes translation as “... the transposition of a text written in a source language into a target language. The translated version must be absolutely accurate in meaning, contain all nuances of the original, and must be written in clear, elegant language that can be easily understood by the reader" (Weber, p. 9, 1984).

Pöchhacker (2004) defines interpreting as one way of translating where an interpreter can orally reproduce the utterance presented in a source language by means of a target language immediately and only once (Pöchhacker, p. 52).

Rabin (1958) describes translation as a process in which oral or written speech in one language expresses exactly the same meaning as a previously or simultaneously presented speech in another language (Rabin, p. 84).

In other words, interpretation is rendition of the message in the source text by means of the target text instantly while it is being uttered. This means that on top of language skills, an interpreter has to have acquired some other skills and abilities the presences of which are dictated by specific characteristics of this job and the work interpreters perform.

In this regard, Sylvia Kalina (2000) in her article "Interpreting competences as a basis and a goal for teaching", claim that interpreters must not only have an excellent command of the general or conversational languages, but also know terms of such specific areas as banking, medicine, ICT, etc. They should distinguish various registers, styles, and have a clear understanding of and strictly adhere to cultural norms.

In other words, the competences of an interpreter fall into the followings two groups: professional and personal. Professional or qualification competences include the knowledge they obtain by studying at university and it includes theoretical wisdom they gain in Linguistics, Translation, History, Sociology, Philosophy, and etc. It is obvious that an interpreter is supposed to speak fluently at least two languages, know the history and culture, social peculiarities and the way of thinking of the people speaking the two working languages.

As for personal competences, Weber (1984) identified the following list of prerequisites for interpreters:

- Intelligence

- Ability to abstract and paraphrase

- Reaction time

- Memory

- Poise and presentation

- Voice

- Understanding of and fluency in the foreign languages

- Quality of the native language (Weber, p. 9)

Proceeding from the above list, we see that an interpreter must be intelligent; and the degree of his/her intelligence must be the same as that of the speaker whose presentation the interpreter is delivering. 
This is also true because only a very experienced translator can instruct students how to avoid pitfall and how to transpose a message written in one language to the genius of another language in such a way that readers of the translation are led to believe that they are actually reading a text drafted in their own language.

What is evident is that interpreters' prerequisite for this performing this task is not limited to intelligence or good memory. Taking into account the mentioned prerequisites, we can consider a group of specialists from Alisher Nava'i Tashkent state university of Uzbek Language and Literature who were appointed to develop a methodology which would involve focusing on both knowledge -oriented and skills-oriented training of interpreters.

The work started with learning from the experience of those who have already made their names in this sphere.

First of all, we organized study trips to national universities where translators and interpreters are trained. These universities include Uzbekistan state world Languages University located in Tashkent and Samarkand state university of foreign languages. These two universities are higher educational establishments with the richest experience in training linguists and interpreters.

During the visit to the universities, we studied their curricula and syllabi; we were shown the literature and materials they use in the educational process. In addition, we also observed their classes.

Moreover, our specialists visited three Russian universities famous for their own school of simultaneous interpreting: Moscow State Linguistic University, Moscow State Institute of International Relations, Nijniy Novgorod State Linguistic University. Programs existing at these universities are run at Master's level (for two years), and there are separate ninemonth courses for those who have a degree from other universities, often of a non-linguistic background, but plan to become interpreters. Each school sticks to its own principles of teaching interpreting which may vary.

In our country, one of the most major challenges is the fact that there are no books or recent attempts to develop material for training interpreters. Some research has been done in translation of fiction, one of which is the work written by I. Tuxtasinov. His research was devoted to developing professional competences of translators on the basis of equivalence. He presented some principles of translating Uzbek prosaic books into English, proposed effective techniques to do it skillfully. A number of novels by prominent Uzbek writers were translated by him using those techniques and were highly appreciated by native speakers. However, his research being targeted at translation fiction does not meet our specific needs.

As for foreign literature, their practical application seems difficult as the language combinations described there do not include Uzbek. Another complexity is that we usually do not have them in full volume. Thus, there is a problem related to the development of a methodological concept of teaching simultaneous interpreting taking into account the circumstances of a linguistic department.

One needs to understand what actions the process of simultaneous interpreting involves and what skills a person needs to have in order to be able to carry out this task.

In this sense, it is worthwhile to consider how interpreters work and what particular performances their task involves. Simultaneous interpreters are simultaneously performing the following actions: 1) listening to the information delivered by the speaker, that is, receiving a message; 2 ) understanding of the meaning, i.e. decoding of the message; 3 ) converting the value to the target language, that is, encoding the message; 4) scoring of the translated version, that is, the release of the message. Each of these actions has a complex hierarchical structure and is produced in real time during limited amount of time (Klonowicz 1994, p. 214).

A.F. Shiryaev distinguishes three phases of (simultaneous interpreting) Sl. Before starting translation, based on their background knowledge, translators build a "probabilistic model of public speaking", which is tested with the beginning of the actual speech of the speaker. If the "pre-setting" of translator was adequate, he can choose the right solution from those already prepared. If a mistake was made in the pre-setting, then the search for a solution is carried out based on experience, knowledge and the guidelines identified in the translation. The first phase ends after a decision is made. The second phase or "implementation phase" includes the completion of the transfer based on the selected model. The last phase is the "control phase" during which an assessment of the correctness of the translation takes place. The first two phases are characterized by transience, while the latter can be "extended in time" (Shiryaev, 1979, pp. 17-18). It is also worth noting that the perception of the text should be carried out at a communicative level using a critical assessment of what is heard (Lapshina, 2005, pp. 74-78). 
The quality of $\mathrm{SI}$ is largely dependent on external (technical) factors and internal (personal) factors.

Some of these factors include complexity caused by the language of signs and symbols as they play equally important role in perceiving a message. Another factor is defined by the work of equipment involved in the process of interpreting, in particular of SI. Prosodic means of speech present one more obstacle for interpreters. They include intonation, syllabic and rhythmic structure of the utterance, pauses, melody, timbre, and tempo. G.V. Chernov was among the first Russian experts in SI who underscored the significance of understanding various accents and its role in interpreting. By accents he means not only British, American, and Australian variants of English but also the English spoken in India, Pakistan, and South and Middle East. (Chernov, p. 166).

As we observe a part from professional competences, simultaneous interpreters have to acquire a lot of additional skills and knowledge before becoming an expert. The path they go along in their professional development is quite complicated and consists of a number of stages.

First of all, to-be-interpreters must master at least two foreign languages. These languages should include at least one language from the official UN languages.

Simultaneous interpreters at the beginning master the consecutive translation of both short segments and long speeches. During the consecutive translation of small fragments, translators rely on memory and mentally divide each passage into several short ones, and for a long segment make notes to simplify the further reproduction of what has been said. During training translators, an integrated approach to teaching consecutive and Sls is very important; it is the subsequent transition from the first type, where translator learn accuracy and completeness of reproduction, to the second, where a high level of concentration is required to apply the skill of listening and speaking simultaneously (Wei Gao, 2011, p. 1).

\section{Results and Discussion}

As it is evident, the first and foremost quality of an interpreter is their knowledge of languages. In this regard, at our university we have decided to pay a particular attention to language teaching.

According to Uzbekistan State standards on education, graduates of bachelor's level must have B2+ level of a language (according to CEFR), and C1 for master's graduates (https://www.lex.uz/acts/359620).

Students studying at Translation Department start pre-interpreting training when they are at Bachelor's level. However, as we mentioned above, most interpreting schools start the actual training of interpreters at Master's. There are a number of reasons which are quite plausible. First of all, when students begin active interpreting training, they should have a foreign language competency at such a level that they do not have any problem neither in understanding the language nor in production of their own thoughts orally and in written from. This competency should be not only in speaking and listening skills but also in grammar and vocabulary command. Moreover, linguistic competences are among the first in the list of professional competences as given in State Standards (https://www.lex.uz/acts/359620).

Nevertheless, there are various approaches regarding to the linguistic competences. Some interpreting schools consider that language development must have been completed before they start learning actual interpreting skills.

At our university, we started implementing activities for developing translation and interpreting skills at the third year of Bachelor's degree. This is when the students have already developed upper-intermediate level in the foreign language.

At bachelor's level, the material used in EFL teaching is made of combination of linguistic and non-linguistic sources. During the first two years, students learn from sources with authentic materials taken from internet, newspapers, podcasts, and such textbooks such as "Gateway to B1", "Gateway to B2", "Navigate", and others. Starting from the third year, the sources are of scientific and political discourse-oriented materials. The newspapers and magazines that are used are "The Economist", "The Guardian", as well as UN and EU speech depositaries. Due to the fact that our graduates are going to work as interpreters in Uzbekistan, they will have to be familiar with the political life in Uzbekistan and abroad. To make them qualified with this knowledge, we also use the addresses and speeches made by the President of Uzbekistan at different meetings and events both in and outside the country.

Another hindrance for simultaneous interpreters is that the text is characterized mainly by linear development and repetition of the structure of the original statement.

To train our students to acquire the ability of producing meaningful translation of the speaker's speech in specific given time, we apply shadowing exercises. We instruct our students to teach them how to echo the speaker with a lag of two to three 
words (Roberts Roda P. Enhancing Short-Term Memory for Accurate Interpreting // The ATA Chronicle. - July 2014. - Vol. XLIII, № 7. - Alexandria, VA (USA): The American Translators Association, 2014. - P. 18-26).

This exercise may or may not involve translation task itself and it may be made more complex by giving additional instructions. For example, we ask our students to listen to the speaker, repeat what she/he said and, after the recording is over, retell the main content. Another task is to expand the gap between the speaker's and students' speaking. For instance, we ask the students to start shadowing when the first sentence ends. This makes them activate their longer-term memory as well as may help them develop their paraphrasing skills.

In addition to this, we also use activities that involve authentic interpreting circumstances when two skills of listening and speaking should be take place simultaneously as if one action in the mind of interpreters overlaps another. One more type of exercise is reading and counting simultaneously when the actual task is to retell the content of the text read in short or in more details depending on the objective of the instructor. This can be complicated by changing the mode of counting or by adding another obstacle by letting them simultaneously listen to a recording with further retelling it. Then, when students become more skillful, we can add the task of translating the text they heard or read while doing some other activities requiring attention split.

However, apart from linguistic and actual interpreting obstacles, students may come across with psychological challenges. In this sense, we can consider the ability to behave in public and overcome shyness which may seem more relevant to consecutive interpreting but it is not less important in the task of simultaneous interpreters. Interpreters must clearly understand the relationship between the speaker and his listeners. Of course, it is not always possible to obtain complete information; however, translators must strive for this in order to become an active listener and a convincing speaker (Thierry 1990: 43).

One useful technique to overcome this problem could be creating authentic conditions for students so that they feel relaxed and at ease in the interpreter's cabin. To do so, especially at the very early stages of interpreter training, we ask them to translate texts of the stories and tales they have known since their childhood; however, to make it closer to reality the teacher shall read the tale in a foreign or native language (they can be interchanged in turns) at a moderate pace and students should try to interpret it. This activity also teaches students to rely on their background knowledge, a prerequisite that is crucial in simultaneous interpreting.

$\mathrm{SI}$ is possible to accomplish, provided that the translator has not only sufficient knowledge of the language but also information about a specific event and affairs taking place in the world in order to be able to fill in the gaps that arise, relying on their own knowledge (Setton, 2005, pp. 71-72).

In many cases interpreters may come across with another problem like missing some information due to various reasons including the accent of or language mistakes produced by the speaker, background noise, or the high speed of speech.

Interpreters should be able to compensate for the missing parts, summarize the message delivered by using contextual and background knowledge, and not try to translate everything. These skills help the translator compensate for losses that have occurred due to the speaker's speech fast rate ambiguity. They must develop the skill of coordinating, splitting attention or switching attention between speaking and listening in order to bring the translation process to a completely automated and coordinated one (Wei Gao, 2011, p. 2).

To survive in such difficult circumstance, interpreters need to be armed with another skill which may be very helpful in their work. It is probabilistic forecasting or anticipation. This skill helps to predict the further coming information (language elements expressing the remaining part of the message). One of the ways to do it is using the "old" information as a bridge to understanding and, accordingly, translating the "new" information into contextual unity. However, such a "contextual" strategy can only be used in cases similar to the one described above. In addition, interpreters may also benefit from their learning a language in chunks. In other words, when students learn a language, they remember not isolated words, but phrases. In many contexts, it helps them to identify the meaning of words. In interpretation it works vice versa. The context and the beginning of a phrase may help them to anticipate which word will follow in a way that they will be able to finish the phrase without waiting for the speaker to express it completely. This is very true in the case of the Uzbek language. In Uzbek, however, the word order is not fixed for any other parts of the sentence but for the predicate. The ability to foresee which word is coming next or to apply a probabilistic forecasting technique becomes crucial when interpreters are working with 
Uzbek-English language combination in which Uzbek sentences always end with verbs and English ones nearly begin with the verb; otherwise, they will have to wait until the speaker ends his/her sentence and only then start translating it.

To develop this skill, we use exercises targeted at developing automaticity. We call them "Ping-Pong" activities. Students are asked to quickly translate Uzbek verbal phrases into English. First, we do it with phrases of noun+ verb model, later we extend the phrase by adding adjectives, adverbs, and changing the composition of the phrase until it grows into a sentence. This can greatly help them in interpreting and prepare them for translating from Uzbek into English at a higher pace.

All of the above-mentioned activities are welcomed by students. They usually do them with enthusiasm and readiness. However, one should always keep in perspective the objectives. They are considered to be effective as long as they prepare students to real life interpreting conditions. Once you find students with no challenges that these games can help to be redressed, you need to implement other activities.

When students become more skilled in interpreting, they may use peer-evaluation activities. This type of activity requires a careful preparation by a teacher as each student must be provided with rubrics and guidance in what to assess and how-to asses. At the beginning, attention can be paid to personal qualities of an interpreter such as her/his voice, intonation, voiced hesitation, tempo of speech, and etc. Then, teachers may include to the list the criteria of a well-structured phrases and sentences, proper usage of synonyms, and correspondence of wording to the original register. However, what is important in this type of activity is the fact that one should be very careful with criticizing. Over criticizing student's mistakes may lead to discouragement and may build a psychological barrier which is really difficult to overcome.

\section{Conclusion}

To conclude, training simultaneous interpreting is very complicated and complex task because it involves a number of objectives to be realized. We made an attempt to generalize existing methodologies by studying the curricula and visiting classes at some universities in Uzbekistan and abroad (mainly Russia). The purpose was to improve the curricula used by some Uzbek universities and to develop a new one for Tashkent state university of Uzbek Language and Literature named after Alisher Navo'i. The most important aspect we paid our attention to were linguistic competency of interpreters, their preparedness to work under stress and pressure, deep and well-structured background knowledge, ability to anticipate the words to be used in phrases, and their ability to apply various techniques that help them in their career of interpreters.

However, we content that there are still gaps to be filled in future researches such as developing exercises that are effective only for interpreters trained in Uzbek-English language combination, piloting them among students and selecting the best ones that could be effective and efficient not only for Uzbek-English interpreters, but also for interpreters translating from other Turkic languages close to Uzbek into English. These languages may include Turkish, Azerbaijani, Kazakh, Kirgiz, and others.

\section{References}

[1] Bordes, S. (2017). La pédagogie de l'interprétation à l'ISIT. N 12-mai 2014, 111.

[2] Gao, W. (2011). Coherence in simultaneous interpreting: an idealized cognitive model perspective (Doctoral dissertation, Heriot-Watt University).

[3] Garzone, G., \& Viezzi, M. (Eds.). (2002). Interpreting in the 21st century: Challenges and opportunities (Vol. 43). John Benjamins Publishing.

[4] Fernández, E. I. (2005). Pochhacker, Franz (2004). Introducing Interpreting Studies. London: Routledge, 252 pp. Sendebar, 16, 286288.

[5] Kalina, S. (2000). Interpreting competences as a basis and a goal for teaching.

[6] Klonowicz, T. (1994). Putting one's heart into simultaneous interpretation. Bridging the gap: Empirical research in simultaneous interpretation, 213-224.

[7] Monacelli, C. (2009). Self-preservation in simultaneous interpreting: Surviving the role (Vol. 84). John Benjamins Publishing.

[8] Rabin, C. (1958). (1958)" The Linguistics of Translation", in Smith (ed.).

[9] Setton, R. (1999). Simultaneous interpretation. A cognitive-pragmatic analysis.

[10] Thiéry, C. (1990). The sense of situation in conference interpreting. Bowen and Bowen (eds)(1990), 40-3.

[11] Viezzi, M. (1993). Considerations on interpretation quality assessment.

[12] Weber, W. K. (1984). Training Translators and Conference Interpreters. Language in Education: Theory and Practice, No. 58. Harcourt Brace Jovanovich International, Orlando, FL 32887.

[13] Лапшина, М.Н. (2005, March). Становление иноязычной коммуникативной компетенции и обучение синхронному переводу. In Материалы XXXIV Международной филологической конференции (рр. 14-19). 
[14] Лапшина, М. Н. (2006, March). Синхронный перевод с английского языка на русский: пути преодоления типичных ошибок. In Материалы XXXV Международной филологической конференции (рр. 13-18).

[15] Лапшина, М. Н. (2006, March). Синхронный перевод с английского языка на русский: пути преодоления типичных ошибок. In Материалы XXXV Международной филологической конференции (рр. 13-18).

[16] Никонова, М.А.(2017). Трудности устного перевода для беженцев и мигрантов. Молодой ученый, (3), 668-672.

[17] Чернов, Г.В.(1978). Теория и практика синхронного перевода. Международные отношения.

[18] Чернов, Г.В., \& Чернов, Г.В.(1987). Основы синхронного перевода.

[19] Ширяев, А. Ф. (1979). Деятельность синхронного переводчика и методика преподавания синхронного перевода. М.: Воениздат. 